\title{
Traçado das curvas-chaves de estações hidrométricas localizadas na bacia hidrográfica do rio Piauí, no estado de Sergipe
}

Construction of rating curves of hydrometric stations located in the basin of Piauí river in the state of Sergipe

\author{
M. H. R. Lima ${ }^{1 *}$; A. P. B. A. Macêdo² \\ ${ }^{1}$ Faculdade Pio Décimo, 49080-470, Aracaju-SE, Brasil \\ ${ }^{2}$ Faculdade Pio Décimo, 49080-470, Aracaju-SE, Brasil, Secretaria do Meio Ambiente e dos Recursos Hídricos, \\ 49030-640, Aracaju-SE, Brasil
}

*hortenciamaria21@hotmail.com

(Recebido em 14 de junho de 2017; aceito em 28 de setembro de 2017)

\begin{abstract}
O conhecimento da disponibilidade hídrica das bacias hidrográficas é de fundamental importância para a gestão de recursos hídricos e elaboração de projetos referentes ao uso da água. A ausência de séries históricas de vazões observadas, entretanto, dificulta a estimativa desse parâmetro. A curva-chave torna-se um mecanismo importante para a gestão de recursos hídricos na medida que possibilita a geração da série histórica das vazões de uma seção de um manancial superficial a partir das medições de nível d'água. Este trabalho teve como objetivo a elaboração das curvas-chaves de quatro estações hidrométricas localizadas na bacia hidrográfica do rio Piauí, no estado de Sergipe. Para o ajuste das curvas utilizou-se uma equação do tipo potência, cujos parâmetros foram determinados pelo método de mínimos desvios quadrados. Observouse que, de modo geral, as medições realizadas retrataram de forma adequada a parte inferior das curvas. $\mathrm{O}$ menor desvio entre os valores de vazão calculados e medidos relativo ao valor do parâmetro $\mathrm{h}_{0}$ selecionado foi observado na estação DESO-SIP (F37).
\end{abstract}

Palavras-chave: hidrometria, monitoramento dos recursos hídricos, medição de vazão.

The knowledge of water availability watershed is of fundamental importance to water resources management and development of projects related to water use. The lack of time series of observed flow rates, however, difficult to estimate this parameter. The rating curve becomes an important mechanism for the management of water resources since that it allows the generation of time series of flow of a section of a surface source from water level measurements. This study aimed to the construction of rating curves of four hydrometric stations located in the basin of Piauí river in the state of Sergipe. For the adjustment of the curves was used an equation of the type power, whose parameters were determined by the method of least squares deviation. It was observed that, in general, the measurements performed properly portrayed the lower part of the curves. The lowest deviation between calculated and measured flow values relative to the value of the selected parameter $\mathrm{h}_{0}$ was observed in the DESO-SIP station (F37).

Keywords: hydrometry, monitoring of water resources, flow measurement.

\section{INTRODUÇÃO}

O conhecimento hidrológico de uma bacia hidrográfica é fundamental para a elaboração dos estudos que norteiam diversas ações relacionadas ao planejamento e à gestão de recursos hídricos e saneamento ambiental, tais como definições sobre medidas estruturais e não estruturais relacionadas aos eventos críticos (secas ou enchentes), projetos de abastecimento público e de lançamento de efluentes, bem como as análises de processos de solicitação de outorga de direito de uso de recursos hídricos [1].

Para essa última ação, que se constitui em um dos instrumentos da Política Nacional de Recursos Hídricos, instituída pela Lei $\mathrm{n}^{\circ}$ 9.433/1997 [2], a estimativa da disponibilidade hídrica nas chamadas seções de controle das bacias hidrográficas, torna-se imperativa.

Verifica-se, entretanto, que o conhecimento hidrológico de um curso d'água requer a disponibilidade de séries históricas de vazões observadas.

$$
109911-1
$$


Os métodos de medição de vazão podem ser enquadrados, de acordo com a natureza da medida, nas categorias estrutural e não estrutural. Na primeira, encontram-se as estruturas de medição previamente calibradas, as quais permitem a determinação da vazão a partir da medição de nível (calha Parshall e vertedores). A segunda engloba os métodos baseados no uso de molinetes, flutuadores, compostos químicos, acústica, dentre outros [3].

Esses processos, em geral, são dispendiosos e envolvem equipamentos e técnicos especializados, o que inviabiliza que as vazões componentes da série histórica sejam obtidas unicamente por meio de medições.

Diante desta dificuldade, a série histórica de vazões é obtida través da curva-chave, que se constitui na relação entre o nível da água (cota) do rio e a sua vazão em uma dada seção.

As medições de cota, por relativamente terem menor custo e serem mais fáceis, podem ser conduzidas com frequência maior do que as medições de vazão, por um observador, em uma estação hidrométrica, ou, de forma automática, por um equipamento de medição de nível [4]. Assim, por meio de uma simples leitura de nível d'água, é possível estimar através da curva-chave, a vazão em uma determinada seção fluvial [5].

Esse trabalho teve como objetivo a elaboração das curvas-chaves de quatro estações hidrométricas localizadas na bacia hidrográfica do rio Piauí, no estado de Sergipe. Essa bacia destaca-se dada a sua importância para o abastecimento d'água de diversas localidades inseridas em seu espaço territorial.

Para o traçado das curvas, utilizaram-se 12 (doze) medições de cotas x vazões, resultantes de campanhas conduzidas no período 2012-2015 no âmbito dos serviços contratados pela Secretaria de Estado do Meio Ambiente e dos Recursos Hídricos (SEMARH) para instalação e operação da rede de monitoramento hidrométrico estadual [6].

As curvas chaves elaboradas foram comparadas com aquelas obtidas no escopo dos serviços supracitados [6].

\section{MATERIAL E MÉTODOS}

As estações hidrométricas selecionadas para o estudo estão inseridas em cursos d'água da bacia do rio Piauí, a qual se constitui em uma das oito bacias hidrográficas pertencentes ao espaço territorial do estado de Sergipe. Essa bacia possui uma área de $4.175 \mathrm{~km}^{2}$, considerando-se a sua porção inserida no estado da Bahia. Quando se considera somente a porção da bacia em Sergipe, a área totaliza $3.953,42 \mathrm{~km}^{2}$, o que equivale a cerca de $19 \%$ do território estadual. Abrange 15 municípios, estando cinco deles totalmente inseridos na bacia [7].

O rio principal desta bacia é o Piauí, que tem uma extensão total de $166,93 \mathrm{~km}$, dos quais 150 km estão no território sergipano. Sua nascente está localizada na Serra de Palmares, entre os municípios de Riachão do Dantas e Simão Dias, desembocando no estuário de Mangue Seco, antes de chegar ao Oceano Atlântico. Tem como principais afluentes os rios Piauitinga, Fundo, Quebradas, Guararema e Arauá [7].

Ao longo do seu percurso, o rio Piauí atravessa três regiões climáticas distintas: a região do Semiárido, que representa $22 \%$ da bacia, apresentando temperaturas que variam de $16^{\circ} \mathrm{C}$ a $36^{\circ} \mathrm{C}$, com evapotranspiração anual de $1500 \mathrm{~mm}$ e pluviometria média anual de $700 \mathrm{~mm}$; a região do Agreste, que representa $30 \%$ da bacia, com temperaturas variando de $34^{\circ} \mathrm{C}$ a $18^{\circ} \mathrm{C}$, com evapotranspiração anual de $1300 \mathrm{~mm}$ e pluviometria média anual de $850 \mathrm{~mm}$ e a região do litoral úmido, que representa $48 \%$ da bacia, exibindo temperaturas que variam de $19^{\circ} \mathrm{C}$ a $32^{\circ} \mathrm{C}$, com evapotranspiração anual de $1400 \mathrm{~mm}$ e pluviometria média anual de $1500 \mathrm{~mm}$ [7].

Em relação a disponibilidade hídrica, observa-se que na porção alta da bacia, a mesma é bastante reduzida, com pequena produção de água, em virtude da ocorrência de rios intermitentes. A parte média da bacia apresenta condições um pouco melhores. A partir deste trecho, o rio Piauí recebe afluentes importantes em produção de água, destacando-se os rios Arauá, Guararema e Indiaroba pela margem direita, e os rios Piauitinga e Fundo pela margem esquerda. Com a entrada destes importantes afluentes, a bacia tem um aumento significativo de sua vazão remanescente atingindo, somente com as entradas dos rios Arauá e Piauitinga, a vazão remanescente de 3,75 m³/s [7]. 
Para o traçado das curvas-chaves foram selecionadas quatro estações hidrométricas da bacia do rio Piauí, as quais integram a rede de monitoramento hidrométrico sob responsabilidade da SEMARH. A identificação das estações selecionadas e a localização espacial das mesmas na bacia hidrográfica do rio Piauí são apresentadas na Tabela 1 e na Figura 1, respectivamente.

Tabela 1: Identificação das estações hidrométricas selecionadas.

\begin{tabular}{|c|c|c|c|c|c|c|}
\hline \multirow{2}{*}{ CÓDIGO } & \multirow{2}{*}{ ESTAÇÃO } & \multirow{2}{*}{$\begin{array}{c}\text { CURSO } \\
\text { D’ÁGUA }\end{array}$} & \multirow{2}{*}{ MUNICÍPIO } & \multicolumn{2}{|c|}{$\begin{array}{c}\text { COORDENADAS } \\
\text { UTM (m) }\end{array}$} & \multirow{2}{*}{$\begin{array}{c}\text { ÁREA DE } \\
\text { DRENAGEM } \\
\left(\mathbf{k m}^{2}\right)\end{array}$} \\
\hline & & & & $\mathbf{N}$ & $\mathbf{E}$ & \\
\hline 50200000 & Caramusse (F25) & Piauí & Boquim & 8.772 .446 & 654.231 & $1.769,68$ \\
\hline 50285000 & Ponte SE-318 (F27) & Indiaroba & Indiaroba & 8.731 .172 & 664.492 & 73,6 \\
\hline 50245000 & Faz. Antas I (F30) & Guararema & $\begin{array}{l}\text { Sta. Luzia do } \\
\text { Itanhy }\end{array}$ & 8.744 .186 & 666.631 & 140,45 \\
\hline 50194000 & DESO-SIP (F37) & Piauitinga & Salgado & 8.783 .302 & 663.904 & 83,83 \\
\hline
\end{tabular}

Fonte: Adaptado de [8].

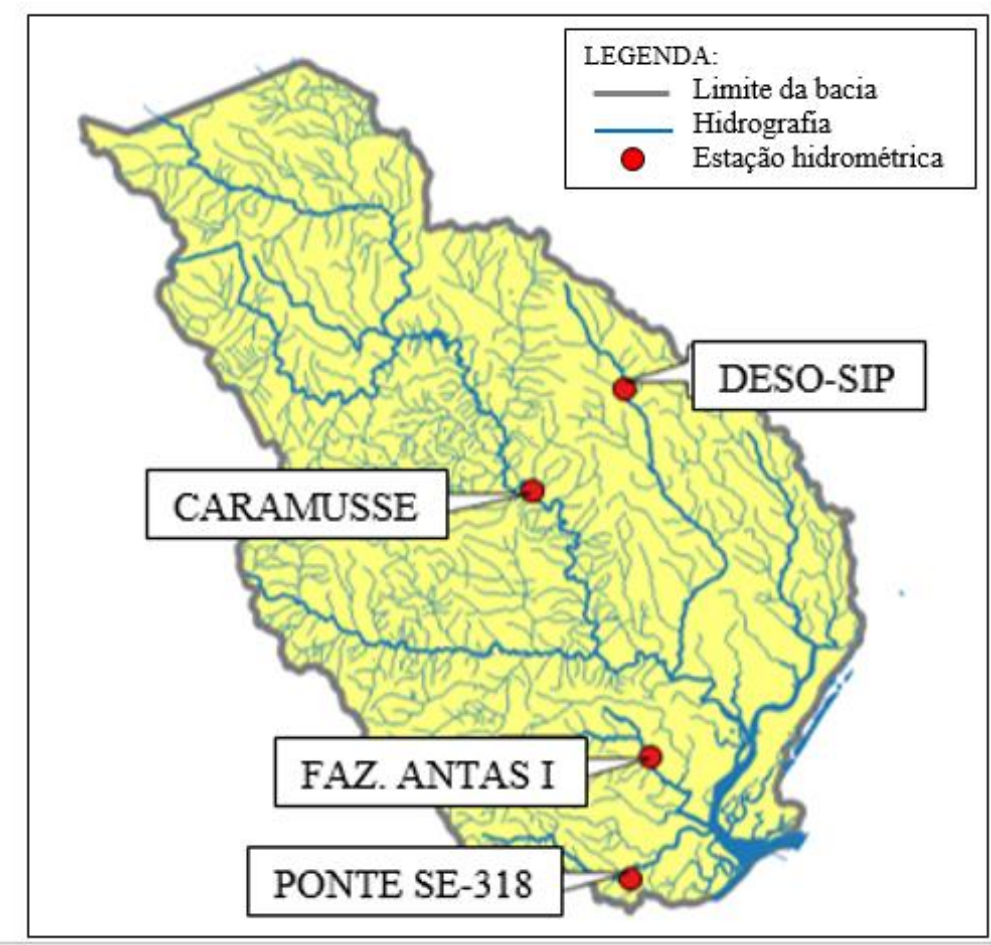

Figura 1: Localização espacial das estações selecionadas na porção da bacia hidrográfica do rio Piauí localizada no estado de Sergipe.

Fonte: [8].

Para construção das curvas-chaves utilizou-se os valores de vazões e níveis d'água registrados a partir do início da operação das estações. Tem-se, para cada estação, um total de 12 medições de vazão disponíveis, realizadas durante o período de novembro de 2012 a abril de 2015.

As curvas chaves foram traçadas a partir do software Microsoft Office Excel 2010. Inicialmente, traçaram-se gráficos $\ln (\mathrm{h}) \mathrm{x} \ln (\mathrm{Q})$ com o intuito de observar como se dava a distribuição.

Para o ajuste das curvas, utilizou-se a Equação 1, do tipo potência, uma vez que esta forma de equação é a preferida pelo fato de ser semelhante ao tipo de relação entre nível d'água e vazão encontrado em equações de escoamento em regime permanente e uniforme, tais como as fórmulas de Manning ou Chezy [4].

$$
\mathrm{Q}=\mathrm{a}\left(\mathrm{h}-\mathrm{h}_{0}\right)^{\mathrm{b}}
$$

onde Q é a vazão $\left(\mathrm{m}^{3} / \mathrm{s}\right)$, h é a cota $(\mathrm{m})$, $\mathrm{h}_{0}$ é a cota quando a vazão é zero $(\mathrm{m})$ e a e b são parâmetros determinados pelo método de mínimos desvios quadrados. Não há um modo ideal de se chegar ao 
valor de $\mathrm{h}_{0}$ [4]. Como o valor desse parâmetro corresponde ao valor de $\mathrm{h}$ para o qual a vazão é igual a zero, considerou-se, inicialmente, na estimativa do mesmo, treze valores de $\mathrm{h}_{0}$ próximos a zero, situados no intervalo de $-0,05$ a $0,05 \mathrm{~m}$. Para cada valor, reajustaram-se os valores de a e b e calculou-se o somatório dos desvios ao quadrado da vazão observada e da vazão calculada pela curva-chave para uma mesma cota. $\mathrm{O}$ valor de $\mathrm{h}_{0}$ selecionado foi aquele correspondente ao valor mínimo do somatório dos desvios ao quadrado. A análise visual da curva-chave também foi considerada.

\section{RESULTADOS E DISCUSSÃO}

O traçado dos gráficos $\ln (\mathrm{Q}) \times \ln (\mathrm{h})$, para cada uma das quatro estações selecionadas, permitiu verificar que a distribuição dos pontos se aproximou de uma reta, com destaque para as estações Fazenda Antas I (F30) e DESO-SIP (F37) (Figura 2).
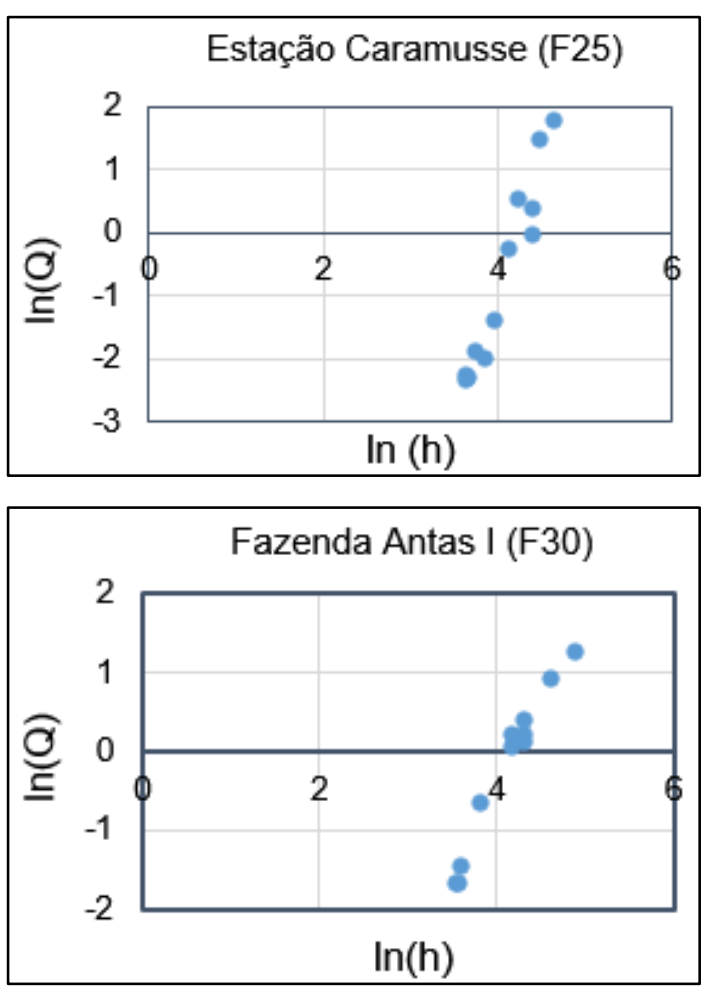
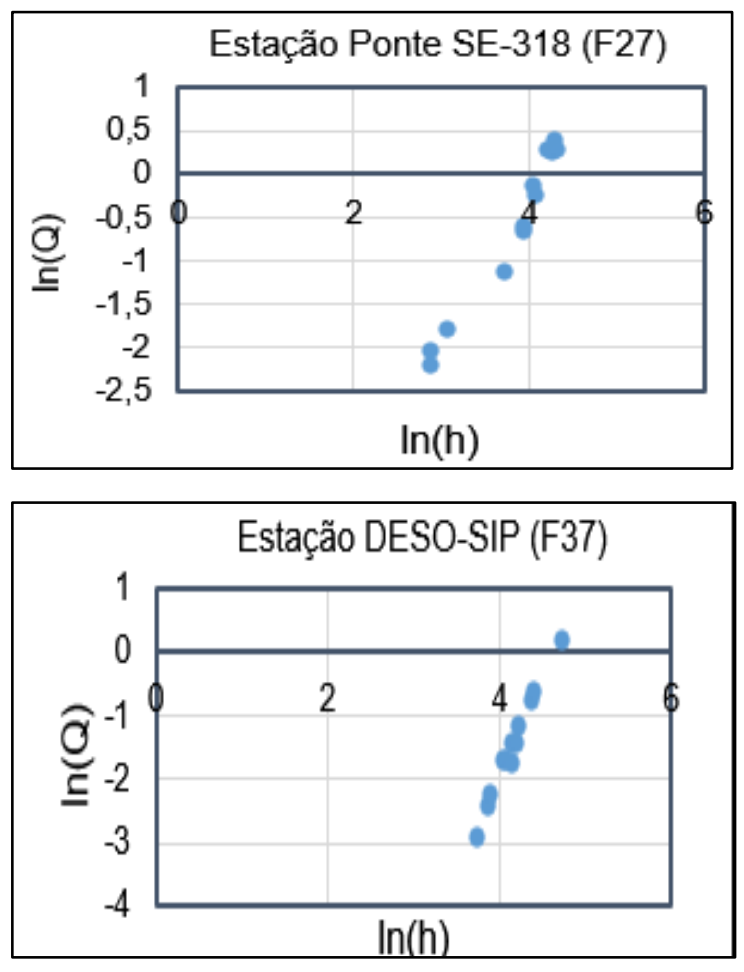

Figura 2: Relação entre os logaritmos dos dados de vazão e nível d'água resultantes das medições nas estações hidrométricas.

Os valores de $\mathrm{h}_{0}$ correspondentes aos valores mínimos dos somatórios dos desvios ao quadrado das vazões observadas e calculadas dentre os treze valores escolhidos são apresentados na Tabela 2. Para a estação Fazenda Antas I (F30), adotou-se um valor de $\mathrm{h}_{0}$ fora da faixa anteriormente citada a fim de possibilitar um melhor ajuste da curva-chave.

Tabela 2: Valores de $h_{0}$ selecionados e respectivos desvios.

\begin{tabular}{lcc}
\hline \multicolumn{1}{c}{ Estação } & $\mathbf{h}_{\mathbf{0}}$ (m) & Desvios \\
\hline Caramusse (F25) & $-0,05$ & 4,16228 \\
Ponte SE-318 (F27) & $-0,05$ & 0,151168 \\
Fazenda Antas I (F30) & 0,25 & 0,179058 \\
DESO-SIP (F37) & 0,05 & 0,019495 \\
\hline
\end{tabular}

Observa-se que as estações DESO-SIP (F37) e Caramusse (F25) apresentaram, respectivamente, o menor e o maior valor de desvio relativo ao valor de $\mathrm{h}_{0}$ selecionado. 
Os valores dos coeficientes a e b correspondentes aos valores de $\mathrm{h}_{0}$ selecionados encontram-se na Tabela 3.

Tabela 3: Valores dos coeficientes a e b.

\begin{tabular}{lcc}
\hline \multicolumn{1}{c}{ Estação } & \multicolumn{1}{c}{ a } & B \\
\hline Caramusse (F25) & $5,7755 \times 10^{-9}$ & 4,38828015 \\
Ponte SE-318 (F27) & 0,00024555 & 1,95178173 \\
Fazenda Antas I (F30) & 0,01073779 & 1,23520324 \\
DESO-SIP (F37) & $1,7218 \times 10^{-6}$ & 2,88611298 \\
\hline
\end{tabular}

Na sequência, apresentam-se as curvas-chaves elaboradas e as respectivas equações (Figuras 3 a 6).

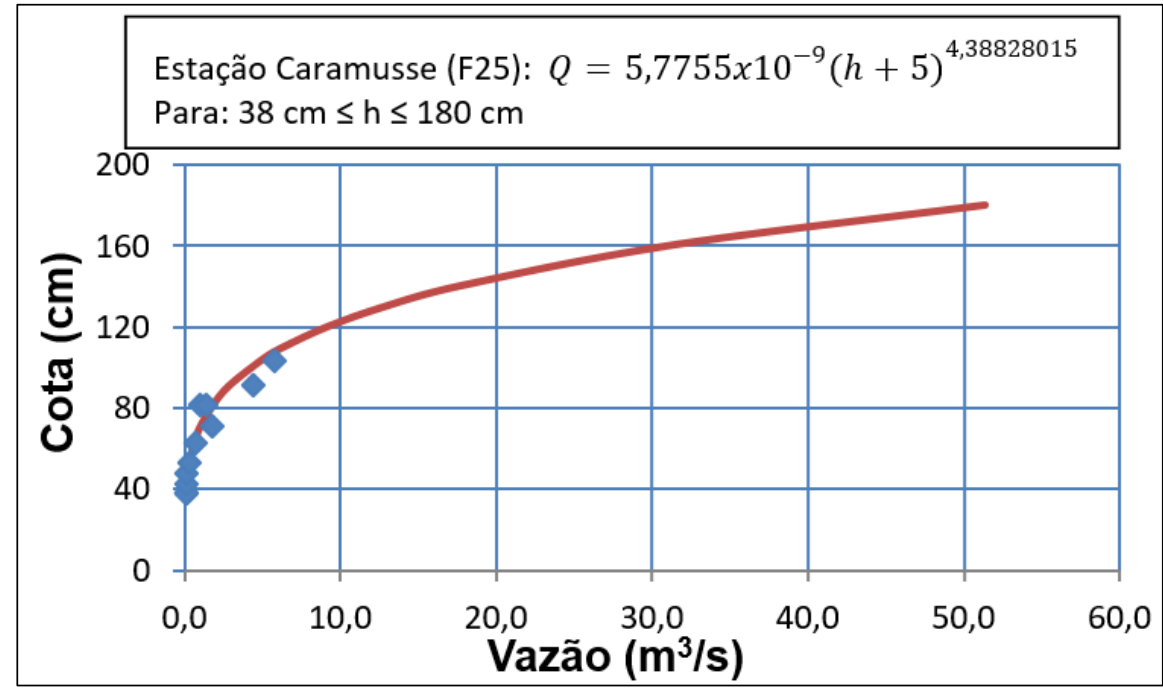

Figura 3: Curva-chave da estação Caramusse (F25).

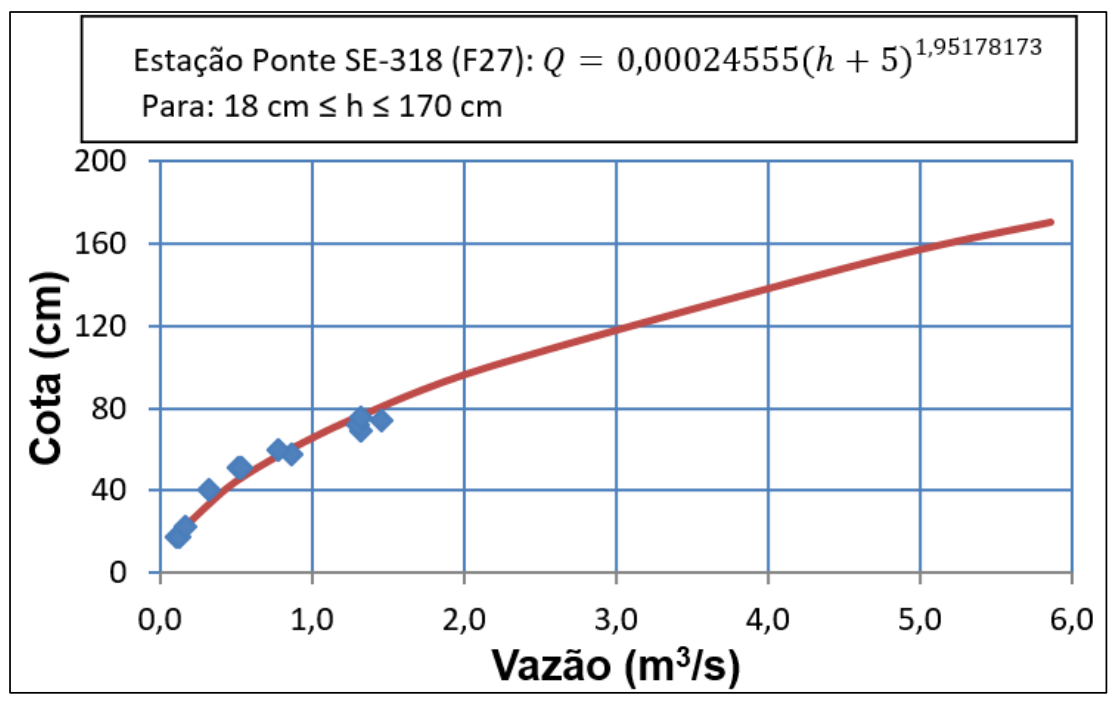

Figura 4: Curva-chave da estação Ponte SE-318 (F27). 


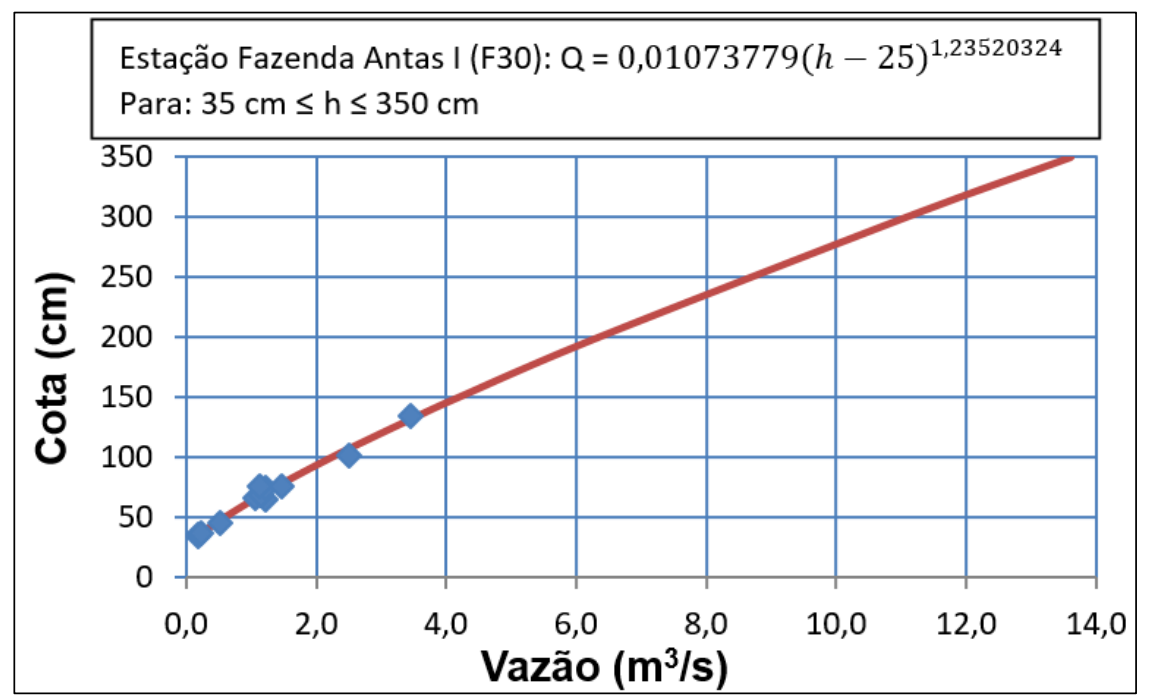

Figura 5: Curva-chave da estação Fazenda Antas I (F30).

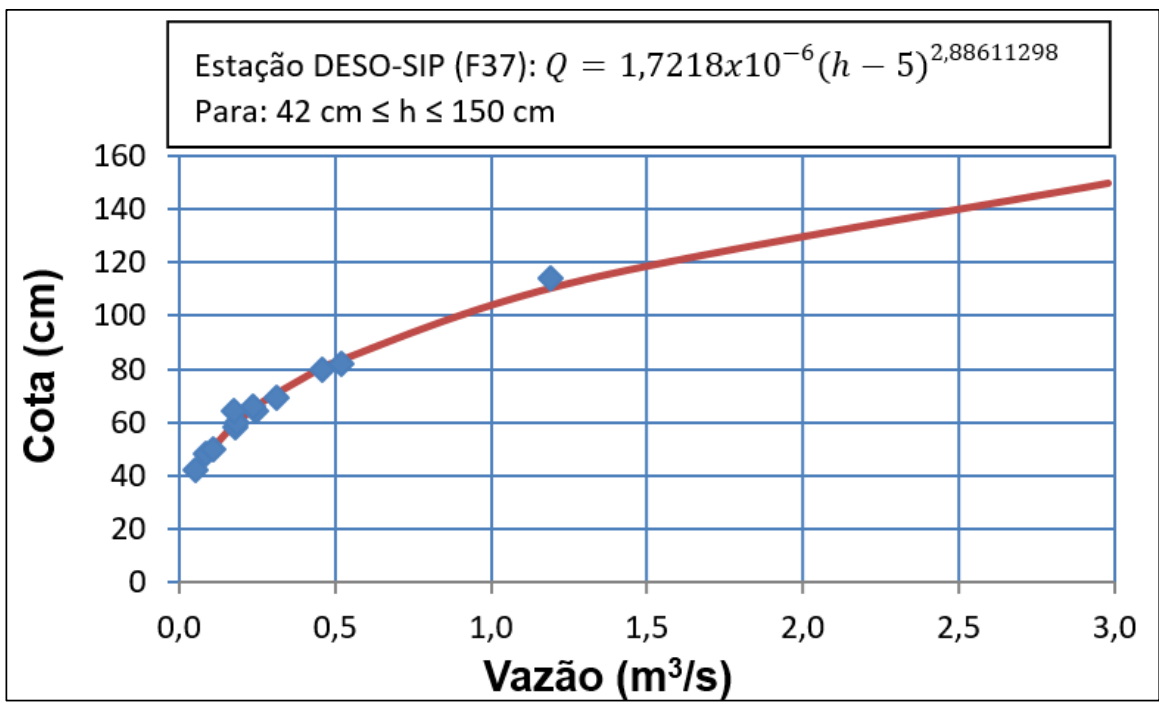

Figura 6: Curva-chave da estação DESO-SIP (F37).

A extrapolação superior das curvas-chaves foi conduzida seguindo-se a tendência do trecho definido pelas medições. A escolha por esse método deve-se ao fato dos dados fluviométricos disponíveis serem insuficientes para aplicação de métodos mais elaborados. Ressalta-se a necessidade de realizar medições de vazão fora do intervalo já medido a fim de confirmar ou retificar as extrapolações superiores das curvas.

Verificou-se que, de modo geral, as medições realizadas retrataram de forma adequada a parte inferior das curvas.

Quando se comparou as curvas-chaves elaboradas no presente trabalho com as curvas obtidas no escopo dos serviços contratados pela SEMARH [6], observou-se ajustes semelhantes. Nesse último estudo, as estações Caramusse e Ponte SE-318 foram ajustadas por meio de equações do tipo potência, enquanto que as estações Fazenda Antas I e DESO-SIP por polinômios de segunda ordem.

\section{CONCLUSÃO}

Observou-se que, de modo geral, as medições realizadas retrataram de forma adequada a parte inferior das curvas, demonstrando que as curvas-chave das estações se mostraram representativas para as baixas vazões. 
Ressalta-se, no entanto, que em virtude do curto período de monitoramento, é de extrema necessidade a realização de medições de vazão fora do intervalo já medido a fim de confirmar ou retificar as extrapolações, tendo em vista que as vazões máximas e mínimas são de grande importância para a gestão de recursos hídricos e aplicação em projetos hidráulicos.

A melhoria no ajuste das curvas-chaves elaboradas neste trabalho, proporcionada com a continuidade do monitoramento hidrométrico, contribuirá para o aprimoramento da estimativa da disponibilidade hídrica na bacia hidrográfica do rio Piauí.

\section{AGRADECIMENTOS}

À SEMARH/SE por fornecer os dados necessários para a realização deste estudo.

\section{REFERÊNCIAS BIBLIOGRÁFICAS}

1. ANA - Agência Nacional de Águas. Medição de descarga líquida em grandes rios: manual técnico. Brasília: ANA; 2009. 88p.

2. BRASIL. Lei n ${ }^{\circ}$ 9.433, de 8 de janeiro de 1997. Institui a Política Nacional de Recursos Hídricos e cria o Sistema Nacional de Gerenciamento de Recursos Hídricos. Presidência da República, Casa Civil, Brasília, DF, 8 jan. 1997. Disponível em: <http://www. planalto.gov.br/ccivil_03/leis/L943 3.htm>. Acesso em: 25 ago. 2017.

3. Paiva JBD, Paiva EMCD. de Hidrologia aplicada à gestão de pequenas bacias hidrográficas. Porto Alegre: ABRH; 2003. 628 p.

4. Collischonn W, Dornelles F. Hidrologia para engenharia e ciências ambientais. Porto Alegre: ABRH; 2013. $336 \mathrm{p}$.

5. Brusa LC, Clarke RT. Erros envolvidos na estimativa da vazão máxima utilizando curva-chave. Caso de estudo: bacia do rio Ibicuí, RS. Revista Brasileira de Recursos Hídricos. 1999 Jul/Set;4(3):91-95, doi:10.21168/rbrh.v4n3.p91-95.

6. SEMARH - Secretaria do Meio Ambiente e dos Recursos Hídricos. Serviços de instalação, operação e manutenção de estações hidrométricas previstas em pontos de monitoramento nas bacias hidrográficas dos rios São Francisco, Japaratuba, Sergipe, Vaza Barris, Piauí e Real, localizadas no estado de Sergipe. Relatório de Consistência ${ }^{\circ}$ 2. Aracaju: SEMARH; 2015.

7. SEMARH - Secretaria do Meio Ambiente e dos Recursos Hídricos. Elaboração dos planos das bacias hidrográficas dos rios Japaratuba, Piauí e Sergipe. Relatório parcial. Aracaju: SEMARH; 2014. 401p.

8. SEMARH - Secretaria do Meio Ambiente e dos Recursos Hídricos. Atlas digital de recursos hídricos de Sergipe. Aracaju: SEMARH; 2014. 